\title{
Evaluation of the nitrate and nitrite content of vegetables commonly grown in Slovenia
}

\author{
Veronika Kmecl, ${ }^{1}$ Tea Knap, ${ }^{2}$ Dragan Žnidarčič3 \\ ${ }^{1}$ Agricultural Institute of Slovenia, Ljubljana; ${ }^{2}$ Faculty of Mathematics, Natural Sciences and Information \\ Technologies, University of Primorska, Koper; ${ }^{3}$ Department of Agronomy, Biotechnical Faculty, University \\ of Ljubljana, Ljubljana, Slovenia
}

\begin{abstract}
Nitrate $\left(\mathrm{NO}_{3}{ }^{-}\right)$and nitrite $\left(\mathrm{NO}_{2}^{-}\right)$levels of a total 1195 samples of nine different vegetables (lettuce, potato, cabbage, carrot, string beans, tomato, cucumber, cauliflower and pepper) collected at several locations of an intensive agricultural area in Slovenia were analysed during a period of 13 years. The content of $\mathrm{NO}_{2}{ }^{-}$ and $\mathrm{NO}_{3}{ }^{-}$ions in commercial mature samples was determined using a segmented flow analyser. The average $\mathrm{NO}_{3}{ }^{-}$content was the highest in lettuce $(962 \mathrm{mg} / \mathrm{kg})$, cabbage $(795 \mathrm{mg} / \mathrm{kg})$, string beans $(298 \mathrm{mg} / \mathrm{kg})$, carrot $(264 \mathrm{mg} / \mathrm{kg})$, cauliflower $(231 \mathrm{mg} / \mathrm{kg})$, potato $(169 \mathrm{mg} / \mathrm{kg})$ and was moderately high in cucumber $(93$ $\mathrm{mg} / \mathrm{kg}$ ) and pepper $(69 \mathrm{mg} / \mathrm{kg})$. A low $\mathrm{NO}_{3}{ }^{-}$content was found in tomato $(<10 \mathrm{mg} / \mathrm{kg})$. The average values of $\mathrm{NO}_{2}{ }^{-}$did not exceed $0.5 \mathrm{mg} / \mathrm{kg}$, with the exception of potato $(1.08 \mathrm{mg} / \mathrm{kg})$. Six samples of lettuce exceeded the maximum permissible level of $\mathrm{NO}_{3}{ }^{-}$ according to current European Union (EU) legislation. Based on the results of our investigation, we assessed the approximate daily intake (DI) of $\mathrm{NO}_{3}{ }^{-}$and $\mathrm{NO}_{2}{ }^{-}$to human body. The results indicated that with the consumption of potato, the daily intake per inhabitant is close to the acceptable DI permitted in EU.
\end{abstract}

Correspondence: Dragan Žnidarčič, Department of Agronomy, Biotechnical Faculty, University of Ljubljana, 1000 Ljubljana, Slovenia.

E-mail: dragan.znidarcic@bf.uni-lj.si

Key words: Cabbage; Lettuce; Nitrate; Nitrite; Slovenia.

Acknowledgements: this work is part of the programme P4-0013-0481 funded by the Slovenian Research Agency (ARRS).

Received for publication: 18 June 2016.

Revision received: 13 October 2016.

Accepted for publication: 15 October 2016.

CCopyright V. Kmecl et al., 2017

Licensee PAGEPress, Italy

Italian Journal of Agronomy 2017; 12:801

doi:10.4081/ija.2017.801

This article is distributed under the terms of the Creative Commons Attribution Noncommercial License (by-nc 4.0) which permits any noncommercial use, distribution, and reproduction in any medium, provided the original author(s) and source are credited.

\section{Introduction}

Nitrates are naturally occurring compounds of nitrogen and the formation of nitrates is an integral part of the nitrogen cycle in the environment. They appear from fertilisers, decaying plants, manure and other organic residues (Prasad and Chetty, 2008). Nitrates are found in the air, soil, water and food. They are also used as a food additive, mainly as a preservative and antimicrobial agent (Walker, 1990; Gangolli et al., 1994; Spejiers, 1996; Speijers and van der Brandt, 2003).

Until recently, concern over the amounts of nitrate and nitrite in our diet has been due to the relationship between nitrate and nitrite and infant methemoglobinemia. The role of nitrites in the formation of carcinogenic nitrosamines has led to some public apprehension about the nitrite content of our food (Knobelock et al., 2000). The nitrate $\left(\mathrm{NO}_{3}{ }^{-}\right)$nitrogen $(\mathrm{N})$ form has a low level of acute toxicity but it can be transformed into the nitrite $\mathrm{N}\left(\mathrm{NO}_{2}{ }^{-}\right)$ form, which has much higher acute toxicity (Santamaria, 2006). It has been estimated that about $4-8 \%$ of the nitrate from the diet may be reduced to nitrite by the micro flora in the oral cavity (Ashby, 2008; Lundberg and Weitzberg, 2009). Some studies have shown that nitrate exposure is correlated with gastric cancer risk due to the endogenous formation of $\mathrm{N}$ - nitroso compounds (Jakszyn and González, 2006).

The intake of nitrite is normally low compared with toxic level doses, but nitrite in food is considered to be a health problem primarily because its presence in both food and the human body may lead to the formation of nitrosamines. Such effects have been shown in animal experiments but their relevance to humans is still uncertain (Nie et al., 2009). There is thus increasing concern about contamination in food, especially vegetables, with nitrate and nitrite (Petersen and Stoltze, 1999; Vaessen and Schothorst, 1999; Ysart et al., 1999). According to Knight et al. (1987) vegetables are generally considered the main source of dietary nitrate in the human diet. Some vegetables, such as Swiss chard (Beta vulgaris L.) (Parks et al., 2008), rape (Brassica campestris L.), Chinese cabbage (Brassica chinensis L.), spinach (Spinacia oleracea L.) (Chen et al., 2004), lettuce (Lactuca sativa L.) (Huett and White, 1992) and salad rocket (Eruca sativa Mill.) (Cavaiuolo and Ferrante, 2014), contain nitrate at significant levels. These vegetables often contain nitrate concentrations above $2500 \mathrm{mg} \mathrm{kg}^{-1}$, especially when they are cultivated in greenhouses (Santamaria, 2006). On the other hand, the nitrate content of vegetables can also be affected by the geographical region, day (light) intensity and duration, soil texture, soil temperature, humidity, density of plants in the field, vegetation period, season of harvest and processing time (Guadagnin et al., 2005; Tamme et al., 2006; Weigtman et al., 2006; Parks et al., 2012).

To protect human health, most European countries have regu- 
lated the nitrate content in food (Santamaria, 2006). Commission Regulation EU No 1258/2011 (European Commission, 2011) amending Regulation EC No 1881/2006 regulates maximum levels for nitrates in vegetables, and these have also been adopted by Slovene regulations (Table 1).

The Joint Expert Committee of Food and Agriculture (JECFA) and the European Commission's Scientific Committee on Food (SCF) have set admissible nitrate and nitrite intake values for the human body. The acceptable daily intake (ADI) for $\mathrm{NO}_{3}{ }^{-}$is $0-3.7$ $\mathrm{mg} \mathrm{kg}-1$ body weight per day and for $\mathrm{NO}_{2}^{-} 0-0.07 \mathrm{mg} \mathrm{kg}^{-1}$ body weight per day. These values are equivalent to $222 \mathrm{mg}$ of $\mathrm{NO}_{3}{ }^{-}$or $4.2 \mathrm{mg}$ of $\mathrm{NO}_{2}^{-}$per day for a $60 \mathrm{~kg}$ adult (Hmeljak and Cencič, 2013). The objective of the research was to determine nitrogen forms and nitrogen rates of nitrate accumulation in various vegetable samples commonly grown in Slovenia and to compare them with relevant legislation. The defined approximate daily intake (ADI) of nitrates and nitrites to the human body were compared with the ADI acceptable in EU. The study was partly based on a previous investigation (Sušin et al., 2006) and was supplemented with new data of nitrate and nitrite daily intake estimates in the Slovene population.

\section{Materials and methods}

\section{Plant material collection}

Over a period of 13 years, nine species of vegetable (lettuce, potato, cabbage, carrot, string beans, tomato, cucumber, cauli- flower and pepper) were included in monitoring, and a total of 859 samples were taken (Table 2). Samples were collected from eight agricultural production areas (Celje, Koper, Kranj, Ljubljana, Maribor, Murska Sobota, Nova Gorica, and Novo Mesto) evenly all over Slovenia (Figure 1). All production areas in this study were managed in accordance with guidelines of the Chamber of Agriculture and Forestry of Slovenia.

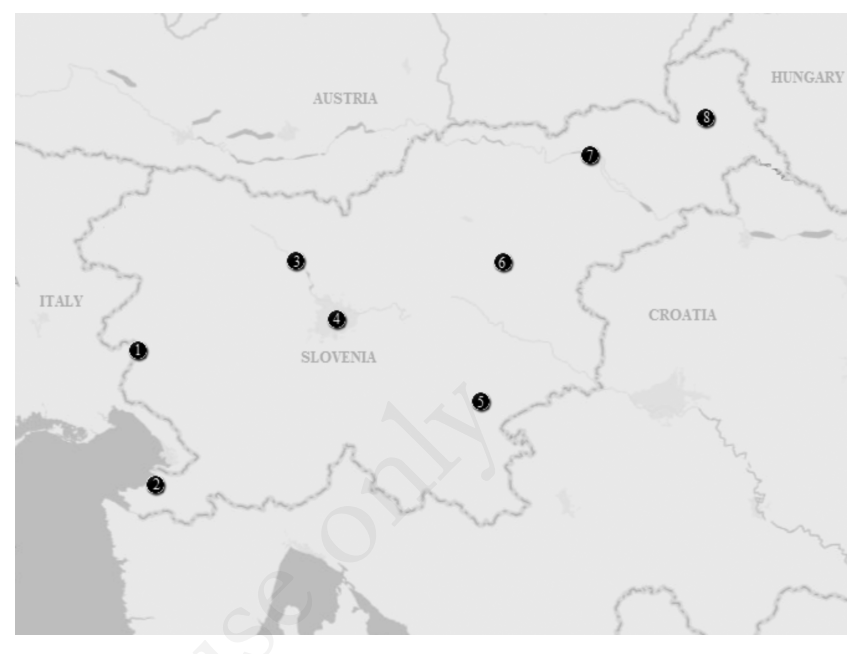

Figure 1. Sampling sites in Slovenia (1-Nova Gorica, 2-Koper, 3Kranj, 4-Ljubljana, 5-Novo Mesto, 6-Celje, 7-Maribor, and 8Murska Sobota).

Table 1. Regulated values of nitrates in foodstuff (European Commission, 2011).

Fresh spinach (Spinacia oleracea)

Preserved, deep frozen or frozen spinach

Fresh lettuce (Lactuca sativa) (greenhouse and open air grown lettuce) excluding Iceberg type lettuce (greenhouse grown lettuce)

Iceberg type lettuce

Rucola (Eruca sativa, Diplotaxis sp., Brassica tenuifolia, Sisymbrium tenuifolium)

Processed cereal-based foods and baby foods for infants and young children

\section{$1^{\text {st }}$ October to $31^{\text {st }}$ March}

$1^{\text {st }}$ October to $31^{\text {st }}$ March (lettuce grown in the open air)

$1^{\text {st }}$ April to $30^{\text {th }}$ September (lettuce grown under cover)

$1^{\text {st }}$ April to $30^{\text {th }}$ September (lettuce grown in the open air)

$1^{\text {st }}$ October to $31^{\text {st }}$ March (lettuce grown under cover)

$1^{\text {st }}$ April to $30^{\text {th }}$ September (lettuce grown in the open air)

$1^{\text {st }}$ October to $31^{\text {st }}$ March

$1^{\text {st }}$ April to $30^{\text {th }}$ September

\section{0}

5000

4000

4000

3000

2500

2000

7000

6000

Table 2. Information of plant samples analysed during thirteen consecutive seasons (2002-2014).

\begin{tabular}{lccc} 
Vegetable & Harvest time & Part of plant & Analysed samples (n) \\
Lettuce & May-October & Leaves & 319 \\
Cabbage & September-October & Vegetative buds & 67 \\
\hline String beans & June-September & Pods & 92 \\
Carrot & July-September & Roots & 65 \\
\hline Cauliflower & September-October & Flowers & 106 \\
Potato & July-September & Tuber & 267 \\
Cucumber & July-September & Fruits & 80 \\
Pepper & August-September & Fruits & 95 \\
\hline Tomato & July-September & Fruits & 104
\end{tabular}


Samples were taken from producers directly at the production sites at the time of commercial maturity of products. Only healthy und undamaged samples, fulfilling market demands, were collected. Immediately after sampling, the samples were taken to the laboratory in polyethylene bags using a portable refrigerator.

\section{Samples preparation}

Among the vegetables that were taken to the laboratory, the leafy part of the sample was analysed in lettuce, the vegetative buds of cabbage, the pods of string beans, the roots of carrot, the flowers of cauliflower, the tubers of potato and the fruits of cucumber, pepper and tomato. Prior to analysis, the fresh plant samples were minced and homogenised and $20 \mathrm{~g}$ of the sample was weighed into a $200 \mathrm{~mL}$ flask, $150 \mathrm{~mL}$ hot deionised water milliQ was added and the flask heated on a water bath for 20 minutes at a temperature of $95^{\circ} \mathrm{C}$. Two $\mathrm{mL}$ of Carezzo solution (300 $\left.\mathrm{g} / \mathrm{L} \mathrm{ZnSO}_{4} \times 7_{2} \mathrm{O}\right)$ and $10 \mathrm{~mL}$ borax solution $\left(50 \mathrm{~g} / \mathrm{L} \mathrm{Na}_{2} \mathrm{~B}_{4} \mathrm{O}_{7} \mathrm{x}\right.$ $10 \mathrm{H}_{2} \mathrm{O}$ ) were added. The flask was filled up to the mark with deionised water milliQ. The extract was filtered through filter paper (Schleicher: Schuell, No. 5891) and the filtrate was analysed according to Naumann and Bassler (1988).

\section{Determination of nitrate and nitrite}

Nitrate and nitrite in vegetables were determined with a Segmented Flow Analyzer (AA II, Bran+Luebbe). The first step was the reduction of nitrate to nitrite on a copper coated cadmium column $\left(\mathrm{NO}_{3}^{-}+2 \mathrm{e}^{-}{ }^{\circledR} \mathrm{NO}_{2}\right)$. The second step was the reaction of nitrites with appropriate reagents to form a colored compound: nitrites react with sulphanilamide under acidic conditions to form a diazo compound. It couples with N-(1-Naphthyl)ethylenediamine dihydrochloride (NEDD) to form a purple azo-dye. dye:

Scheme of transformation of $\mathrm{NO}_{2}{ }^{-}$into redish-purple azo-

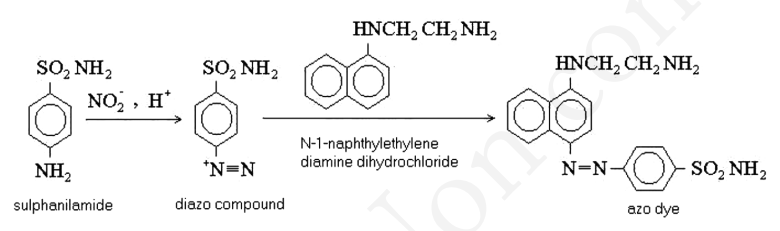

The intensity of colored compound was measured photometrically by a Segmented Flow Analyzer at a wavelength of $540 \mathrm{~nm}$. The result is the sum of nitrate and nitrite. To express only the nitrate, the preliminarily determined nitrite must be subtracted.

A flow diagram for determination of $\mathrm{NO}_{3}{ }^{-}$in vegetable samples by continuous flow analysis (CFA) $\left(\mathrm{San}^{++}\right)$is also presented in Figure 2.

\section{Confirmation of quality assessment data}

The method for determination of nitrates in vegetables is accredited in our Agrochemical Laboratory of the Agricultural Institute of Slovenia (Kmecl and Žnidarčič, 2015). The accuracy of measurements was verified in collaboration with the Dutch international inter-laboratory comparative scheme WEPAL (Wageningen Evaluating Programme for Analytical Laboratories) and the French comparative scheme BIPEA (Bureau Interprofessionnel d'Etudes Analytiques). The values found were within the $95 \%$ confidence interval for the test materials.

\section{Data analysis and calculation of daily intake of nitrate and nitrite}

Data were statistically analysed for each vegetable separately using the statistical software package R ( R Development Core Team, 2010). Classical descriptive statistics was done. We determined the median content of $\mathrm{NO}_{3}{ }^{-}$and/or $\mathrm{NO}_{2}{ }^{-}$, the coefficient of variation within an individual vegetable, the class in which the vegetable can be placed according to the median content and the number of individual samples analysed.

From the obtained data we calculated the daily intake (DI) of nitrates and nitrites into the human body. DI was calculated on estimations based on annual vegetable consumption per inhabitant.

\section{Results and discussion}

\section{Content of the nitrate form in vegetables}

The nitrate content of selected vegetables in Slovenia is presented in Figure 3. The results obtained show a considerable variation in the nitrate content within the same vegetable species. As

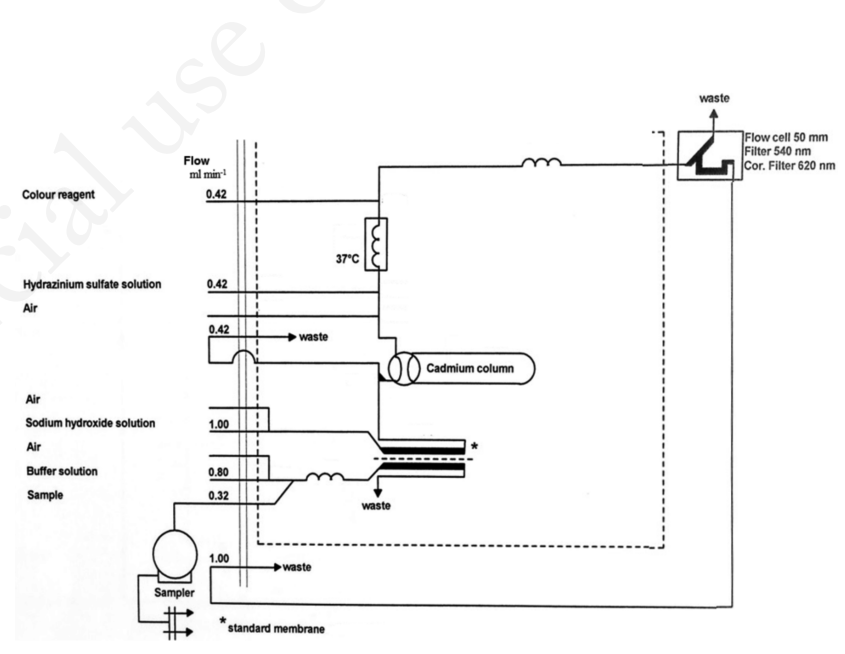

Figure 2. Flow diagram for determination of nitrate in vegetable samples by continuous flow analysis (San++).

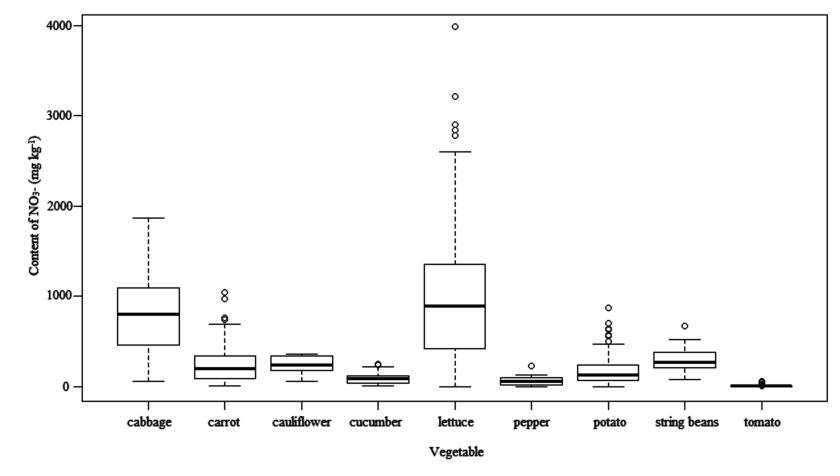

Figure 3. Box plots of nitrate contents $\left(\mathrm{mg} \mathrm{kg}^{-1}\right)$ in nine vegetables across all locations. Boxes encompass the upper and lower quartiles, while the line indicates the median. Circles are outliers. 
previously described, the nitrate content in vegetables depends on many factors, such as soil properties, fertiliser usage, cultivation and weather conditions, which are unknown and whose effects are impossible to account for in this study. Considering all these different factors, wide ranges and large standard deviation may occur (Pennington, 1998). On the other hand, the differentiation in nitrate concentration can be explained by the variable intensity of metabolic processes in the different organs of plants (Kovacik, 1994). This may also explain the high variation among the findings presented in this study. Leafy vegetables (lettuce and cabbage) accumulated the highest nitrate content compared to other vegetables. A high amount of $\mathrm{NO}_{3}{ }^{-}$was found in lettuce but the median concentration of it was $962 \mathrm{mg} \mathrm{kg}^{-1}$. The range of $\mathrm{NO}_{3}^{-}$in cabbage was from 56 to $1964 \mathrm{mg} \mathrm{kg}^{-1}$, and it was under maximum levels for leafy vegetables. The obtained results appear to be about $200 \%$ higher than the values reported by Yordanov et al. (2001) and Czech et al. (2012) in their studies on cabbage harvested in Bulgaria and Poland. It seems that lettuce contributes to the highest dietary nitrate intake from vegetables in Slovenia. DeMartin and Restani (2003) in Italy, Tamme et al. (2006) in Estonia, Merino et al. (2006) in Sweden and Menard et al. (2008) in France also found a very high content of nitrate in lettuce. On the other hand, some findings did not agree with these reports. For example, Fytianos and Zarogiannis (1999) in Greece reported that the nitrate content in lettuce was $282 \mathrm{mg} / \mathrm{kg}^{-1}$. Some researchers have suggested (Hsu et al., 2009) that this dissimilarity may be due to horticultural practices, such as the use of nitrate-based fertilisers. The median nitrate contents for vegetables such as string beans, carrot, cauliflower and potato (100 to $300 \mathrm{mg} \mathrm{kg}^{-1}$ of $\mathrm{NO}_{3}^{-}$) were similar and comparable to the results obtained for vegetables in other European countries, particularly those reported in Italy (DeMartin and Restani, 2003 ) and Poland (Jaworska, 2005). String beans accumulated the most nitrates $\left(298 \mathrm{mg} \mathrm{kg}^{-1}\right)$, followed by cauliflower $\left(231 \mathrm{mg} \mathrm{kg}^{-1}\right)$, carrot $\left(264 \mathrm{mg} \mathrm{kg}^{-1}\right)$ and potato $\left(169 \mathrm{mg} \mathrm{kg}^{-1}\right)$. Moderate concentrations of $\mathrm{NO}_{3}^{-}$were found in cucumber $\left(93 \mathrm{mg} \mathrm{kg}^{-1}\right)$ and pepper (69 $\mathrm{mg} \mathrm{kg}^{-1}$ ). The least nitrates were found in tomato samples (on average $3 \mathrm{mg} \mathrm{kg}^{-1}$ ), although the coefficient of variation was high. Present legislation in the European Union regulates the maximum values of nitrates in spinach, lettuce, rucola and processed cerealbased foods (Table 1). When the analysed values of nitrates in lettuce were compared to the prescribed limits, six samples out of a total of 319 exceeded the maximum admissible value.

\section{Content of the nitrite form in vegetables}

The results for nitrite in vegetables are shown in Figure 4. The nitrite content in vegetables was not as high as that of nitrate. This observation is consistent with the results of Petersen and Stoltze (1999) and Correia et al. (2010), who found only minor quantities of nitrites in several vegetables.

The highest nitrites were found in potato, with a median concentration of $1.08 \mathrm{mg} \mathrm{kg}^{-1}$. The range of individual samples was between LOQ and $7.64 \mathrm{mg} \mathrm{kg}^{-1}$ of $\mathrm{NO}_{2}^{-}$. Due to the very high coefficient of variation (100\%), some samples deviated markedly from the average value. In other vegetable samples, the average nitrite concentration was under $0.3 \mathrm{mg} \mathrm{kg}^{-1}$. A high variability of nitrite measurements was observed in lettuce, tomato and cucumber samples $(\mathrm{CV}=60-100 \%)$, in which the range of $\mathrm{NO}_{3}{ }^{-}$was between LOQ and 1.58. Although vegetables contain a minor amount of nitrite, this can be increased significantly by microbiological reduction of nitrate if they are stored incorrectly. It was suggested by Zhong et al. (2002) that this is especially a problem for leafy vegetables, because soil adhering to them may be difficult to remove completely.

\section{Nitrate and nitrite forms intake by human body}

According to Hmeljak and Cencič (2013), the primary variables for nitrate intake are the type of vegetables consumed, the levels of nitrate in the vegetables and the amount of vegetables consumed. For example, Van Velzen et al. (2008) reported that nitrate from leafy vegetables is absorbed very effectively, resulting in an absolute nitrate bioavailability of around $100 \%$.

Based on the data obtained, we calculated the daily intake (DI) of nitrates and nitrites and compared it with the acceptable daily intake (ADI) valid in he European Union. The DI was calculated on estimations based on annual vegetable consumption per inhabitant over a period of 13 years. The results indicated that potato is the most consumed agricultural product in Slovenia (the average consumption per inhabitant is as high as $74.8 \mathrm{~kg}$ potato per year) (Table 3).

The average nitrate content of 267 potato samples was $169 \mathrm{mg}$ $\mathrm{kg}^{-1}$ (Table 4). In terms of potato consumption, the nitrate DI is $34.6 \mathrm{mg}$ per inhabitant. Considering the maximum measured nitrate content of potato $\left(871 \mathrm{mg} \mathrm{kg}^{-1}\right)$, the DI increase to $179 \mathrm{mg}$

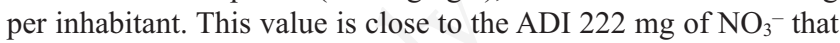
is permitted in the EU. The nitrate daily intake of lettuce and cabbage samples is $79.9 \mathrm{mg}$ per inhabitant (lettuce) and $67.8 \mathrm{mg}$ per inhabitant (cabbage) and $33.7 \mathrm{mg}$ per inhabitant (carrot) considering the maximum measured content of nitrates in both cultures. The DI for other vegetables (string beans, tomato, cucumber, cauliflower and pepper) does not reach even $10 \mathrm{mg}$ of $\mathrm{NO}_{3}{ }^{-}$per inhabitant (Table 4). If the potential intakes of nitrate from vegetables in

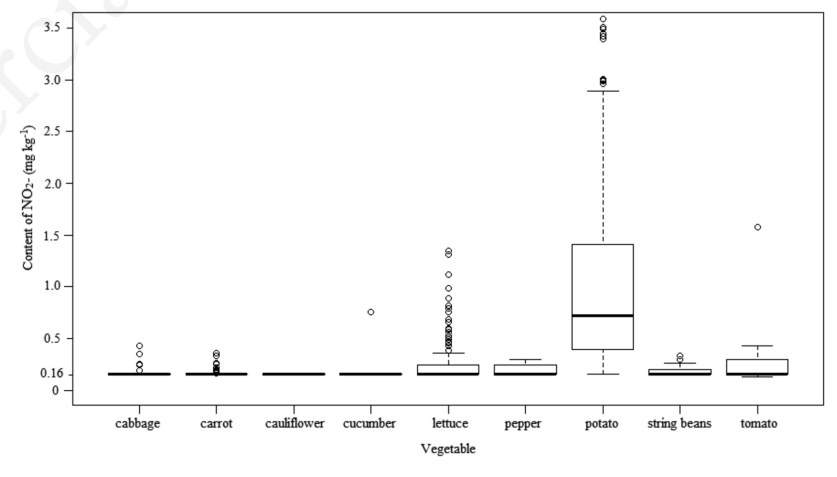

Figure 4. Box plots of nitrite contents $\left(\mathrm{mg} \mathrm{kg}^{-1}\right)$ in nine vegetables across all locations. Boxes encompass the upper and lower quartiles, while the line indicates the median. Circles are outliers. Limit of quantification is at $0.16 \mathrm{mg} \mathrm{kg}^{-1}$.

Table 3. Consumption of vegetables (kg) per inhabitant per year in Slovenia.

Vegetable Average (2002-2014)
Consumption (kg/inh.)/year

\begin{tabular}{lc} 
Lettuce & 6.4 \\
Cabbage & 12.6 \\
\hline String beans & 4.4 \\
Tomato & 18.6 \\
\hline Cucumber & 3.4 \\
Cauliflower & 1.6 \\
\hline Carrot & 11.8 \\
Pepper & 6.2 \\
\hline Potato & 74.8
\end{tabular}


Table 4. Nitrate intake (Slovenian inhabitant per day).

\begin{tabular}{|c|c|c|c|c|c|}
\hline Vegetable & $\begin{array}{l}\text { Content of } \mathrm{NO}_{3}^{-} \\
\left.(\mathrm{mg} \mathrm{kg})^{-1}\right) \\
\text { (average value) }\end{array}$ & $\begin{array}{l}\text { Content of } \mathrm{NO}_{3}^{-} \\
{[(\mathrm{mg} / \mathrm{inh} .) / \text { day }]} \\
\text { (average value) }\end{array}$ & $\begin{array}{c}\text { Content of } \mathrm{NO}_{3}^{-} \\
\left(\mathrm{mg} \mathrm{kg}^{-1}\right) \\
\text { (max value) }\end{array}$ & $\begin{array}{l}\text { Content of } \mathrm{NO}_{3}^{-}, \\
\text {[(mg/inh.)/day] } \\
\text { (max value) }\end{array}$ & $\begin{array}{c}\text { Coefficient } \\
\text { of variation (\%) }\end{array}$ \\
\hline Lettuce & 962 & 16.9 & 3986 & 79.9 & 70 \\
\hline Cabbage & 795 & 27.4 & 1964 & 67.8 & 60 \\
\hline String beans & 298 & 3.6 & 675 & 8.1 & 50 \\
\hline Tomato & 6.4 & 0.3 & 60 & 3.1 & 150 \\
\hline Cucumber & 93 & 1.0 & 245 & 2.3 & 70 \\
\hline Cauliflower & 231 & 1.0 & 360 & 1.6 & 50 \\
\hline Pepper & 69 & 1.2 & 225 & 3.8 & 90 \\
\hline Potato & 169 & 34.6 & 871 & 179 & 80 \\
\hline Carrot & 264 & 8.5 & 1042 & 33.7 & 90 \\
\hline
\end{tabular}

Acceptable daily intake $\left(\mathrm{NO}_{3}^{-}\right): 3.7 \mathrm{mg} \mathrm{kg}^{-1}$ body weight day ${ }^{-1}\left(=222 \mathrm{mg}\right.$ for $\left.60 \mathrm{~kg}^{\text {person}}\right)$.

Table 5. Nitrite intake (Slovenian inhabitant per day).

\begin{tabular}{|c|c|c|c|c|c|}
\hline Vegetable & $\begin{array}{l}\text { Content of } \mathrm{NO}_{2}^{-} \\
\quad\left(\mathrm{mg} \mathrm{kg} \mathrm{g}^{-1}\right) \\
\text { (average value) }\end{array}$ & $\begin{array}{l}\text { Content of } \mathrm{NO}_{2}^{-} \\
{[(\mathrm{mg} / \mathrm{inh} .) / \mathrm{day}]} \\
\text { (average value) }\end{array}$ & $\begin{array}{l}\text { Content of } \mathrm{NO}_{2}^{-} \\
\left(\mathrm{mg} \mathrm{kg} \mathrm{kg}^{-1}\right) \\
(\max \text { value) }\end{array}$ & $\begin{array}{l}\text { Content of } \mathrm{NO}_{2}^{-}, \\
\text {[(mg/inh.)/day] } \\
\text { (max value) }\end{array}$ & $\begin{array}{c}\text { Coefficient } \\
\text { of variation }(\%)\end{array}$ \\
\hline Lettuce & 0.28 & 0.01 & 1.35 & 0.02 & 70 \\
\hline Cabbage & 0.17 & 0.01 & 0.43 & 0.01 & 30 \\
\hline String beans & 0.18 & 0.002 & 0.33 & 0.004 & 20 \\
\hline Tomato & 0.25 & 0.01 & 1.58 & 0.08 & 80 \\
\hline Cucumber & 0.18 & 0.002 & 0.76 & 0.01 & 60 \\
\hline Cauliflower & $<0.16$ & l & $<0.16$ & l & I \\
\hline Pepper & 0.20 & 0.003 & 0.30 & 0.01 & 30 \\
\hline Potato & 1.08 & 0.22 & 7.64 & 1.57 & 100 \\
\hline Carrot & 0.17 & 0.005 & 0.36 & 0.01 & 20 \\
\hline
\end{tabular}

Acceptable daily intake $\left(\mathrm{NO}_{2}^{-}\right): 0.07 \mathrm{mg} \mathrm{kg}^{-1}$ body weight day-1 $(=4.2 \mathrm{mg}$ for $60 \mathrm{~kg}$ person).

Slovenia is compared with those in other European countries, it appears that the nitrate intake estimated in this study is substantially higher than the intake estimates reported from the UK (Knight et al., 1987), Denmark (Petersen and Stoltze, 1999), Italy (De Martin and Restani, 2003), Estonia (Tamme et al., 2006) and France (Menard et al., 2008). The most likely explanation for this difference is the higher consumption of vegetables in Slovenia. The situation was similar in the assessment of dietary intake of nitrites (Table 5). Only potato samples contained higher concentrations of $\mathrm{NO}_{2}^{-}$(maximum content was $7.64 \mathrm{mg} \mathrm{kg}{ }^{-1}$ ) and we estimated a nitrite intake of $1.57 \mathrm{mg}$ of $\mathrm{NO}_{2}^{-}$per inhabitant per day. This result is half of the value for the acceptable daily intake for nitrite (ADI: $4.2 \mathrm{mg}$ of $\mathrm{NO}_{2}^{-}$; for $60 \mathrm{~kg}$ person). Our investigation indicates that none of the other crops (lettuce, cabbage, string beans, tomato, cucumber, cauliflower and pepper) are a matter of concern for nitrite intake.

\section{Conclusions}

Growing concern over nitrate toxicity has produced a number of studies on the nitrate and nitrite contents of fresh vegetable samples. Nitrite and nitrate levels of nine vegetable samples from an intensive horticultural area in Slovenia were analysed over a peri- od of 13 years and their levels compared to those reported in recent literature. The results are in the range of others reported in different European countries. The most nitrates were found in leafy vegetables, i.e. lettuce and cabbage. We determined average values of $\mathrm{NO}_{3}{ }^{-}$between 700 and $1000 \mathrm{mg} \mathrm{kg}^{-1}$ in these crops. Six of a total of 319 lettuce samples (2\%) exceeded the maximum admissible value recommended by the EU. According to present knowledge, ingestion of the studied vegetables is considered to be beneficial for the population despite their nitrate and nitrite contents.

\section{References}

Ashby MT, 2008. Inorganic chemistry of defensive peroxidases in the human oral cavity. J. Dent. Res. 87:900-14.

Cavaiuolo M, Ferrante A, 2014. Nitrates and glucosinolates as strong determinants of the nutritional quality in rocket leafy salads. Nutrients 6:1519-38.

Chen BM, Wang ZH, Li SX, Wang GX, Song HX, Xi-Na W, 2004. Effects of nitrate supply on plant growth, nitrate accumulation, metabolic nitrate concentration and nitrate reductase activity in three leafy vegetables. Plant Sci. 167:635-43.

Correia M, Barroso A, Barroso F, Soaresa D, Oliveira MBPP, Delerue-Matos C, 2010. Contribution of different vegetable 
types to exogenous nitrate and nitrite exposure. Food Chem. 120:960-6.

Czech A, Pawlik M, Rusinek E, 2012. Contents of heavy metals, nitrates, and nitrites in cabbage. Pol. J. Environ. Stud. 21:3219.

De Martin S, Restani P, 2003. Determination of nitrates by a novel ion chromatographic method: Occurrence in leafy vegetables (organic and conventional) and exposure assessment for Italian consumers. Food Addit. Contam. 20:787-92.

European Commission, 2011. Commission regulation amending regulation (EC) No 1881/2006 as regards maximum levels for nitrates in foodstuffs, 1258/2011/EU. In: Official Journal, L 320/15, 03-12-2011.

Fytianos K, Zarogiannis P, 1999. Nitrate and nitrite accumulation in fresh vegetables from Greece. B. Environ. Contam. Tox. 62:187-92.

Gangolli SD, van den Brandt P, Feron V, Janzowsky C, Koeman J, Speijers G, Speigelhalder B, Walker R, Winshnok J, 1994. Assessment of nitrate, nitrite, and N-nitroso compounds. Eur. J. Pharm.-Environ. 292:1-38.

Guadagnin SG, Rath S, Reyes FGR, 2005. Evaluation of the nitrate content in leaf vegetables produced through different agricultural systems. Food Addit. Contam. 22:1203-8.

Hmeljak Gorenjak A, Cencič A, 2013. Nitrate in vegetables and their impact on human health. A review. Acta Aliment. Hung. 42:158-72.

Hsu J, Arcot J, Lee NA, 2009. Nitrate and nitrite quantification from cured meat and vegetables and their estimated dietary intake in Australians. Food Chem. 115:334-9.

Huett DO, White E, 1992. Determination of critical nitrogen concentrations of lettuce (Lactuca sativa L cv montello) grown in sand culture. Aust. J. Agr. Res. 32:759-69.

Jakszyn P, González CA, 2006. Nitrosamine and related food intake and gastric and oesophageal cancer risk: A systematic review of the epidemiological evidence. World J. Gastroenterol. 12:4296-303.

Jaworska G, 2005. Content of nitrates, nitrites and oxalates in New Zealand spinach. Food Chem. 89:235-42.

Kmecl V, Žnidarčič D, 2015. Accreditation of analytical method used for determination of nitrate in vegetable. Arch. Biol. Sci. 67:295-302.

Knight TM, Foman O, Aldabbagh SA, Doll R, 1987. Estimation of dietary intake of nitrate and nitrite in Great Britain. Food Chem. Toxicol. 25:277-85.

Knobelock L, Salna B, Hogan A, Postle J, Anderson H, 2000. Blue babies and nitrate-contaminated well water. Environ. Health Persp. 108:675-8.

Kovacik P, 1994. The sites of higher nitrate accumulation in some vegetables and the influence of soil substrate on nitrate content. Pol'nohospodarstvo 40:755-62.

Lundberg JO, Weitzberg E, 2009. NO generation from inorganic nitrate and nitrite: role in physiology, nutrition and therapeutics. Arch. Pharm. Res. 32:1119-26.

Menard C, Heraud F, Volatier JL, Leblanc JC, 2008. Assessment of dietary exposure of nitrate and nitrite in France. Food Addit. Contam. 25:971-88.

Merino L, Darnerud PO, Edberg U, Aman P, Castillo MDP, 2006. Levels of nitrate in Swedish lettuce and spinach over the past 10 years. Food Addit. Contam. 23:1283-9.

Naumann K, Bassler R, 1988. Die Chemische Untersuchung von Futtermitteln, 3ed. J Naumann Neudamm, Darmstadt, Germany.

Nie S, Gao W, Chen Y, Sui P, Eneji AE, 2009. Review of current status and research approaches to nitrogen pollution in farmlands. Agr. Sci. China 8:843-9.

Parks SE, Huett DO, Campbell LC, Spohr LJ, 2008. Nitrate and nitrite in Australian leafy vegetables. Aus. J. Agr. Res. 59:6329.

Parks SE, Irving DE, Milhamc PJ, 2012. A critical evaluation of on-farm rapid tests for measuring nitrate in leafy vegetables. Sci. Hortic. 134:1-6.

Pennington JAT,1998. Dietary exposure models for nitrtes and nitrites. Food Control 9:385-95.

Petersen A, Stoltze S, 1999. Nitrate and nitrite in vegetables on the Danish market: content and intake. Food Addit. Contam. 16:291-9.

Prasad S, Chetty AA, 2008. Nitrate-N determination in leafy vegetables: study of the effects of cooking and freezing. Food Chem. 106:772-80.

R Development Core Team, 2010. R: a language and environment for statistical computing $\mathrm{R}$ Foundation for Statistical Computing, Vienna, Austria. Available from: https://www.rproject.org/

Santamaria P, 2006. Nitrate in vegetables: toxicity, content, intake and EC regulation. Food Addit. Contam. 86:10-7.

Speijers GJA, 1996. Nitrate. In: Toxicological evaluation of certain food additives and contaminants in food. WHO Food Additives Series 35. World Health Organization, Geneva, Switzerland, pp. 325-60.

Speijers GJA, van den Brandt PA, 2003. Nitrite and potential endogenous formation of N-nitroso compounds. Food Addit. 50:269-323.

Sušin J, Kmecl V, Gregorčič A, 2006. A survey of nitrate and nitrite content of fruit and vegetables grown in Slovenia during 19962002. Food Addit. Contam. 23:385-90.

Tamme T, Reinik M, Roasto M, Juhkam K, Tenno T, Kiis A, 2006. Nitrates and nitrites in vegetables and vegetable-based products and their intakes by the Estonian population. Food Addit. Contam. 23:355-61.

Vaessen HA, Schothorst RC, 1999. The oral nitrate and nitrite intake in the Netherlands: evaluation of the results obtained by PHLC analysis of duplicate 24-hour diet samples collected in 1994. Food Addit. Contam. 16:181-8.

Van Velzen AG, Sips AJAM, Schothorst RC, Lambers AC, Meulenbelt J, 2008. The oral bioavailability of nitrate from nitrate-rich vegetables in humans. Toxicol. Lett. 181:177-81.

Walker R, 1990. Nitrates, nitrites and N-nitrosocompounds: a review of the occurrence in food and diet and the toxicological implications. Food Addit. Contam. 7:717-68.

Weightman RM, Dyer C, Buxton J, Farrington DS, 2006. Effects of light level, time of harvest and position within field on the variability of tissue nitrate concentration in commercial crops of lettuce (Lactuca sativa) and endive (Cichorium endiva). Food Addit. Contam. 23:462-9.

Ysart G, Clifford R, Harrison N, 1999. Monitoring for nitrate in UK-grown lettuce and spinach. Food Addit. Contam. 16:3016.

Yordanov ND, Novakova E, Lubenova S, 2001. Consecutive estimation of nitrate and nitrite ions in vegetables and fruits by electron paramagnetic resonance spectrometry. Anal. Chim. Acta 437:131-8.

Zhong W, Hu C, Wang M, 2002. Nitrate and nitrite in vegetables from north China: content and intake. Food Addit. Contam. 19:1125-9. 